\title{
Virtual Inertia Control Methods in Islanded Microgrids
}

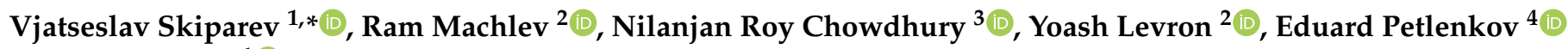 \\ and Juri Belikov ${ }^{1}$ (D) \\ 1 Department of Software Science, Tallinn University of Technology, 12618 Tallinn, Estonia; \\ juri.belikov@taltech.ee \\ 2 The Andrew and Erna Viterbi Faculty of Electrical Engineering, Technion-Israel Institute of Technology, \\ Haifa 3200003, Israel; ramm@campus.technion.ac.il (R.M.); yoashl@ee.technion.ac.il (Y.L.) \\ 3 Shamoon College of Engineering, Beer-Sheva 84100, Israel; nilanjan2008@gmail.com \\ 4 Department of Computer Systems, Tallinn University of Technology, 12618 Tallinn, Estonia; \\ eduard.petlenkov@taltech.ee \\ * Correspondence: vjatseslav.skiparev@taltech.ee
}

check for

updates

Citation: Skiparev, V.; Machlev, R.; Chowdhury, N.R.; Levron, Y.;

Petlenkov, E.; Belikov, J. Virtual

Inertia Control Methods in Islanded

Microgrids. Energies 2021, 14, 1562.

https:/ / doi.org/10.3390/en14061562

Academic Editor: David Schoenwald

Received: 13 February 2021

Accepted: 3 March 2021

Published: 11 March 2021

Publisher's Note: MDPI stays neutral with regard to jurisdictional claims in published maps and institutional affiliations.

\begin{abstract}
Although the deployment and integration of isolated microgrids is gaining widespread support, regulation of microgrid frequency under high penetration levels of renewable sources is still being researched. Among the numerous studies on frequency stability, one key approach is based on integrating an additional loop with virtual inertia control, designed to mimic the behavior of traditional synchronous machines. In this survey, recent works related to virtual inertia control methods in islanded microgrids are reviewed. Based on a contextual analysis of recent papers from the last decade, we attempt to better understand why certain control methods are suitable for different scenarios, the currently open theoretical and numerical challenges, and which control strategies will predominate in the following years. Some of the reviewed methods are the coefficient diagram method, H-infinity-based methods, reinforcement-learning-based methods, practical-swarm-based methods, fuzzy-logic-based methods, and model-predictive controllers.
\end{abstract}

Keywords: frequency control; islanded microgrid; renewable energy; virtual inertia control

\section{Introduction}

Renewable energy sources (RESs) are frequently deployed in modern power grids to promote a myriad of environmental and economical benefits. However, the increasing integration of RESs significantly decreases the rotational inertia of the grid, which jeopardizes grid stability and its overall dynamic behavior [1-4]. A central challenge is regulating the grid's frequency under high penetration levels of renewable sources. One approach for addressing this problem is to install fast-reacting storage systems with virtual inertia controllers alongside low-inertia power sources; such controllers have been extensively studied in recent years [5-11]. Each control method has its own benefits and limitations. For instance, classical control paradigms are simple in general but are designed for specific scenarios, whereas data-driven algorithms are flexible and enable online learning. However, these algorithms are numerically complex and require adequate data to operate efficiently. Hybrid control strategies have low numeric complexity, but their convergence is hard to guarantee in most cases. Proposing suitable guidelines for choosing the best algorithm is currently an open question, and this question becomes more important when the microgrid is isolated [11-17].

Microgrids have received increasing attention as a means of integrating distributed generation into the electricity grid [18]. Usually described as confined clusters of loads, storage devices, and small generators, these autonomous networks connect as single entities to the public distribution grid through a point of common coupling (PCC). Figure 1 illustrates a typical microgrid network. Microgrids comprise a variety of technologies: renewable sources, such as photovoltaic and wind generators, are operated alongside 
traditional high-inertia synchronous generators, batteries, and fuel-cells. Thus, energy is generated near the loads, enabling the use of small-scale generators that increase reliability and reduce losses over long power lines. The locality of the microgrid network enables the improved management of energy. Generators (and possibly loads) may be controlled by a local energy management system to optimize power flow within the network. The objectives of energy management depend on the mode of operation: islanded or gridconnected [19]. In grid-connected mode, the typical objectives are to minimize the price of energy import at the PCC, to improve power factor at the PCC, and to optimize the voltage profile within the microgrid [20]. In islanded mode, which is addressed in this paper, the main goal of power management is to stabilize the system and preserve high reliability and resiliency in terms of frequency and voltage.

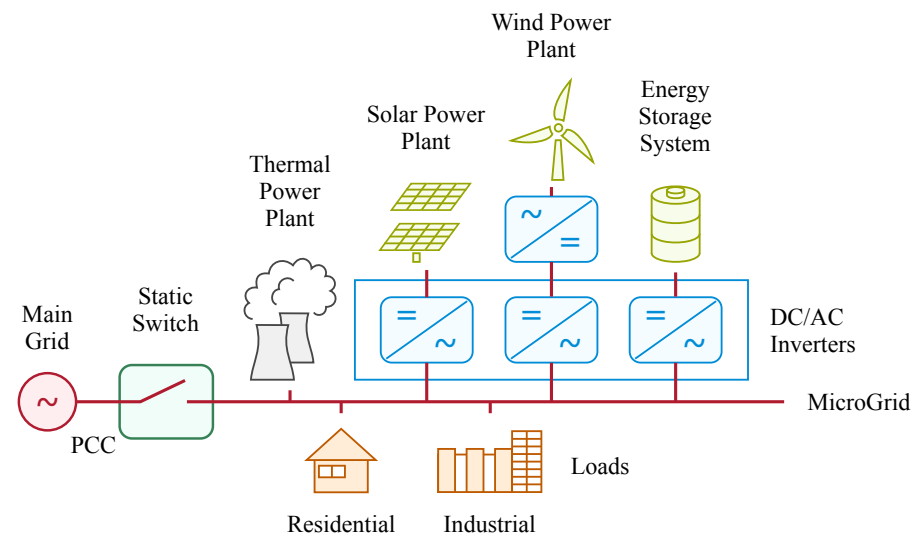

Figure 1. Schematic representation of a typical microgrid. PCC-point of common coupling.

Few recent survey papers describe different aspects in the context of virtual inertia within power grids with a high penetration of RESs. A comprehensive review of virtual inertia implementation techniques was provided in [12]. The reviewed works were classified and compared using virtual inertia topologies. Some selected topologies were simulated, showing that similar inertial responses can be achieved, relating the parameters of these topologies through time and inertia constants. A discussion of the challenges and research directions is presented, indicating future research needs for the integration of virtual inertia systems. Singh et al. [21] reviewed various topologies for emulating a virtual inertia algorithm along with control strategies for general distributed generation. They also reviewed the optimal size and location of synthetic inertia in a power system. Other authors [22] presented a review focusing on the inertia values for power systems. The inertia values were estimated based on different regions in the last 20 years. The contribution of photovoltaic (PV) power plants as virtual inertia was discussed and the damping factor evolution was analyzed.

Contrary to these comprehensive reviews, which focused on virtual inertia topologies implementation [12], virtual inertia and frequency control for distributed energy sources [21], and inertia estimation evolution in power systems [22], we focused on the systematic comparison of virtual inertia control methods designed to solve the frequency regulation problem in islanded microgrids. In particular, we aimed to understand why certain control methods are more efficient in different circumstances, and which control strategies will gain popularity in the coming years. Toward this end, we considered different control techniques available in the literature for the period of 2010-2020, and then categorized them into three groups: classic, advanced, and hybrid methods. We provide a detailed analysis of each control and optimization paradigm through various quality criteria. Finally, we provide a contextual analysis and highlight the current developments and trends for various combinations of virtual inertia control methods and technologies with a focus on microgrid applications. 
The rest of this paper is organized as follows: Section 2 presents a model of a standard low-inertia microgrid and explains different control quality criteria. Section 3 summarizes the classical methods applied for virtual inertia control, followed by a discussion of the advanced control methods presented in Section 4. Hybrid control algorithms are described in Section 5. Section 6 provides an analysis of recent trends in low-inertia power systems and virtual inertia control.

\section{Overview of Low-Inertia Microgrid System}

The low-inertia microgrid encompasses participants with different power generation inertia and loads with complex dynamics [23-26]. Therefore, microgrids with high RES penetration pose various challenges for integration to the massive distribution networks such as (1) active/reactive power imbalance and voltage droop in transmission lines, (2) production/consumption imbalance in distribution loads, and (3) frequency mismatch with other microgrids and the rest of the power grid [3,27]. Hence, energy storage systems are considered the prime actuator in frequency stability control, which, in reality, have physical limitations such as (1) (dis)charge cycles, (2) restricted power reservation, (3) reserved power losses, and (4) individual speed of (dis)charge. Moreover, energy storage control performed by virtual inertia or a virtual synchronous generator (VSG) uses power-inverting electronics, which has delays in frequency measurement and power conversion [12,28-32].

\subsection{Modeling of a Low-Inertia Microgrid}

The considered microgrid was adopted from several recent publications [16,33-37] and is depicted in Figure 2. The addressed scenario includes simplified residential/industrial loads, energy sources (thermal power plant, wind farm, and solar power plant), and energy storage systems $[11,38,39]$. The thermal power plant is composed of a governor with a generator rate constraint (GRC) and a turbine with a frequency rate limiter, which restricts the valve opening/closing ( $V_{U}$ and $V_{L}$, respectively). The dynamic model of a microgrid uses a hierarchical architecture with primary and secondary control loops. The primary control loop has a droop coefficient $1 / R$, and the secondary loop has an area control error (ACE) system with a second frequency controller $K_{I}$ and a first-order integrator. Frequency regulation is performed by a virtual inertia device with an additional controller. The balancing system is performed as the first-order transfer function with microgrid damping coefficient $D$ and system inertia $H$, which are common for all generators. The power generation by variable energy sources is modeled as a random signal with a first-order holder. The hierarchical structure includes the reservation of the primary and secondary control loops. The modeling parameters of the microgrid are summarized in Table 1; Table 2 lists the typical simulation scenarios available in the recent literature.

Table 1. Nomenclature: microgrid parameters.

\begin{tabular}{ll}
\hline Variable & Physical Meaning \\
\hline$\Delta P_{m}$ & Generated power change from the distributed generator \\
$T_{t}$ & Time constant of the turbine \\
$\Delta P_{g}$ & Governor valve-position change \\
$T_{g}$ & Time constant of the governor \\
$\Delta P_{A C E}$ & Control signal change for secondary control \\
$K_{I}$ & Integral control variable gain \\
$\Delta P_{W}$ & Change in generated power-based wind farm \\
$\Delta P_{\text {wind }}$ & Initial wind power variation \\
$T_{W T}$ & Time constant of wind turbines \\
$\Delta P_{P V}$ & Change in generated power-based solar farm \\
$\Delta P_{\text {solar }}$ & Initial solar power variation \\
$T_{P V}$ & Time constant of the solar system \\
$\Delta P_{L}$ & Load power change \\
$\Delta P_{R L}$ & Variations in residential loads \\
$\Delta P_{I L}$ & Variations in industrial loads \\
\hline
\end{tabular}




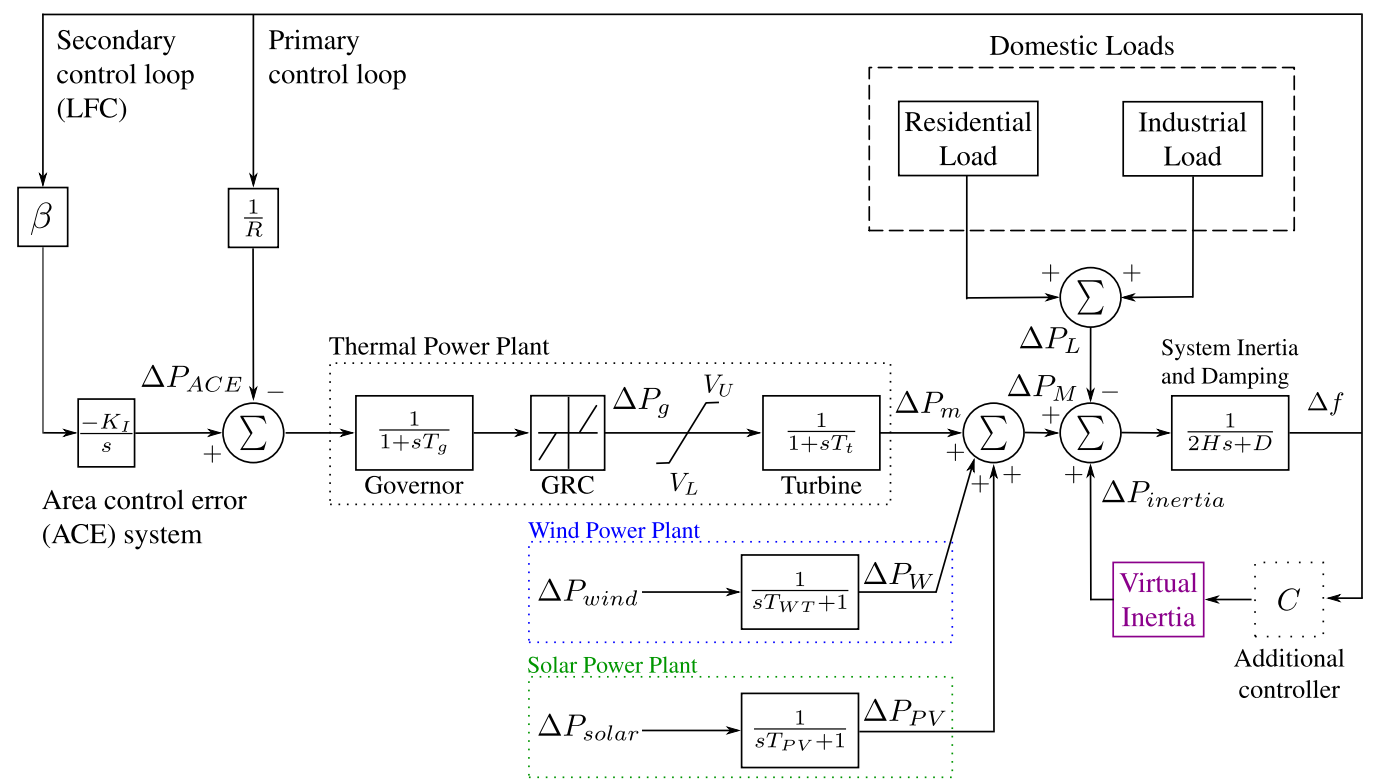

Figure 2. Schematic representation of an islanded microgrid with hierarchical control. GRCgenerator rate constant; LFC-load-frequency control.

\subsection{Frequency Regulation in Low-Inertia Power Systems}

Frequency stability is important when low-inertia energy sources penetrate the grid in large amounts $[1,40,41]$. For example, the wind turbine rotor of a synchronous generator has natural inertia, which plays a key role in the power compensation for short periods (up to $5 \mathrm{~s}$ ) [3]. Solar panels may be considered as zero-inertia generators, since they do not provide physical energy storage [42]. The response of frequency deviation is defined by the rate of change of frequency $(\mathrm{RoCoF})$, which can be calculated as follows $[43,44]$ :

$$
\operatorname{RoCoF}=\frac{\mathrm{d}(\Delta f)}{\mathrm{d} t} .
$$

The magnitude of the RoCoF reflects the balanced state in the dynamics of renewable power sources. The problem is generating an active power resembling that generated by traditional power plants.

Table 2. Nomenclature: dynamic parameters of islanded microgrids in different scenarios.

\begin{tabular}{|c|c|c|c|c|c|c|c|}
\hline Name & $\begin{array}{l}\text { Uncertainty } \\
\text { Parameter }\end{array}$ & $\begin{array}{l}\text { Nominal } \\
\text { Value }\end{array}$ & Scenario 1 & Scenario 2 & Scenario 3 & Scenario 4 & Scenario 5 \\
\hline System inertia & $\begin{array}{c}H \text { (p.u. MW } \\
\text { s) }\end{array}$ & $95-100 \%$ & $80 \%$ & $40-50 \%$ & $25-30 \%$ & $15 \%$ & $10 \%$ \\
\hline Droop characteristic & $\begin{array}{l}R(\mathrm{~Hz} / \mathrm{p} . \mathrm{u} . \\
\mathrm{MW})\end{array}$ & 2.4 & 2.4 & 2.4 & $1.8-2.4$ & 2.4 & 1.2 \\
\hline Time constant of governor & $T_{g}(\mathrm{~s})$ & $0.1-0.12$ & 0.1 & 0.1 & $0.1-0.15$ & 0.1 & 0.175 \\
\hline Time constant of turbine & $T_{t}^{o}(\mathrm{~s})$ & $0.4-0.975$ & 0.4 & 0.4 & $0.4-0.7$ & 0.4 & 0.7 \\
\hline $\begin{array}{l}\text { Time constant of solar } \\
\text { panel }\end{array}$ & $T_{P V}(\mathrm{~s})$ & $1.8-1.85$ & 1.85 & $1.8-1.85$ & 1.8 & 1.85 & 1.85 \\
\hline $\begin{array}{l}\text { Time constant of wind } \\
\text { turbine }\end{array}$ & $T_{W T}(\mathrm{~s})$ & 1.5 & 1.5 & 1.5 & 1.5 & 1.5 & 1.5 \\
\hline $\begin{array}{l}\text { Integral control variable } \\
\text { gain }\end{array}$ & $K_{i}(\mathrm{~s})$ & 0.05 & 0.05 & 0.05 & $0.04-0.05$ & 0.05 & 0.03 \\
\hline $\begin{array}{l}\text { System damping coeffi- } \\
\text { cient }\end{array}$ & $\begin{array}{c}D(\text { p.u. } \\
\mathrm{MW} / \mathrm{Hz})\end{array}$ & $0.015-0.0195$ & 0.015 & 0.015 & $0.0135-0.015$ & 0.015 & 0.003 \\
\hline Frequency bias & $\begin{array}{c}\beta \text { (p.u. } \\
\text { MW/Hz) }\end{array}$ & 1.0 & 1.0 & 1.0 & $0.8-1.0$ & 1.0 & 0.7 \\
\hline
\end{tabular}


Table 2. Cont.

\begin{tabular}{|c|c|c|c|c|c|c|c|}
\hline Name & $\begin{array}{l}\text { Uncertainty } \\
\text { Parameter }\end{array}$ & $\begin{array}{l}\text { Nominal } \\
\text { Value }\end{array}$ & Scenario 1 & $\begin{array}{c}\text { Scenario } \\
2\end{array}$ & Scenario 3 & Scenario 4 & Scenario 5 \\
\hline $\begin{array}{l}\text { Virtual inertia control } \\
\text { gain }\end{array}$ & $K_{V I}$ & $0.5-0.8$ & 1.0 & 1.0 & $0.8-1.0$ & 1.0 & 0.4 \\
\hline $\begin{array}{l}\text { Virtual inertia time } \\
\text { constant }\end{array}$ & $T_{V I}(\mathrm{~s})$ & 10 & 10 & 10 & 10 & 10 & 11 \\
\hline $\begin{array}{l}\text { Virtual inertia control } \\
\text { power limiter }\end{array}$ & $\Delta P_{\text {inertia }, \max / \mathrm{r}}$ & in $0.25-0.3$ & $0.25-0.3$ & $0.25-0.3$ & 0.3 & 0.3 & 0.25 \\
\hline Valve gate speed & $V_{U / L}$ & $0.3-0.5$ & 0.5 & $0.1-0.5$ & $0.1-0.5$ & 0.3 & 0.5 \\
\hline $\begin{array}{l}\text { Time constant phased } \\
\text { locked-loop (PLL) }\end{array}$ & $\omega_{n}(\mathrm{~s})$ & 1.5 & - & - & - & - & 0.3 \\
\hline References & & $\begin{array}{c}{[16,33,35-} \\
37,45]\end{array}$ & {$[34,37]$} & $\begin{array}{l}{[16,33,34,} \\
37,45,46]\end{array}$ & {$[16,34]$} & [33] & [35] \\
\hline
\end{tabular}

\subsection{Virtual Inertia Control}

The virtual synchronous generator (VSG) produces the power alternative to the real synchronous machine $[47,48]$. This generator can be applied in systems with a high level of fluctuating renewable power to enhance the frequency stability. Virtual inertia (VI) is a specific part of the VSG designed to compensate for the lack of inertia using a power injection mechanism [3]. The default operational limitations of the virtual inertia device cannot provide reliable frequency support. Therefore, an additional robust controller must be used to deal with nonlinearities in low-inertia environments. Traditionally, the virtual inertia control setup (Figure 3) consists of a derivative component, a designed controller $K(s)$, virtual inertia control (energy storage system and virtual inertia variable gain), and a power limiter $\left(\Delta P_{\text {inertia, } \max }, \Delta P_{\text {inertia }, \min }\right)$.

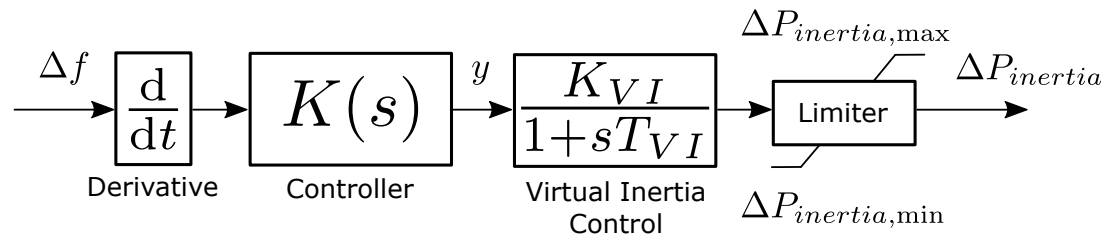

Figure 3. Typical structure of a virtual inertia control block.

\subsection{Energy Storage System}

The energy storage system (ESS) has been implemented in various physical realizations $[38,49,50]$. The technology can be directly incorporated into frequency-response services and support the RoCoF during a frequency event. For the last decade, ESSs became an essential component in renewable energy integration, since they may provide frequency smoothness and balance for further dispatch [5,51-57]. The simplified ESS model can be represented as follows:

$$
G(s)=\frac{1}{T_{V I} s+1} .
$$

\subsection{Hierarchical Control}

Hierarchical frequency control introduces a multilevel cascade system with three key layers: primary, secondary (load frequency control), and tertiary control, and two additional layers: internal generation control and high-level policy control. Primary control is responsible for regulation of individual elements: power sharing, frequency droop, and local voltage control. Secondary control is oriented toward the balancing of active and reactive power by determination of the set-points of the primary controller and secondary control, including grid synchronization, automatic generation control (AGC), secondary load-frequency control (LFC), and voltage-drop control. Tertiary control (i.e., reserved) is 
related to energy management. It is used to provide optimal power flow and steady-state conditions in a distribution network [3,58-61].

\subsection{Control Quality Criteria}

In this section, we discuss typical control criteria. They are then used to examine the benefits and drawbacks of the presented algorithms.

- Online learning. Real-time optimization is used to adapt controllers to varying conditions [62,63], and usually requires a special computational device for additional tuning, validation, and verification.

- Robustness. Flexible reaction to disturbances is an important requirement in lowinertia power grids, since, in practice, frequency deviation is limited to the range of $\pm 0.1-1.5 \mathrm{~Hz}[12,64-68]$, and Nadir requirements are $\pm 0.024 \mathrm{~Hz}[12,69]$. Using this criterion, we briefly describe testing scenarios and the performance of the considered virtual inertia controller.

- Implementation complexity. Complexity corresponds to the implementation efforts of an algorithm in real controlling hardware: size, number of inputs and outputs, mathematical complexity, etc.

- Optimization difficulty. This depends on the number of inputs and outputs, time for optimization procedure, and other requirements for the computational power to provide the maximum possible efficiency.

\subsection{Description of the Virtual Inertia Control Algorithms}

Several recent works $[12,16,33-36,70,71]$ addressed the problem of optimal frequency support with high penetration of variable renewable energy sources. For example, Kerdphol et al. [35] designed a robust $H_{\infty}$ controller to provide stability support based on the rate of change of frequency. The proposed solution provides advantages over conventional virtual inertia control and optimally tuned proportional integral (PI) controllers in scenarios when the wind farm is connected, solar panels are disconnected, and the system inertia is $10 \%$ and $100 \%$, respectively. Kerdphol et al. [34] further studied the problem by implementing a virtual inertia control scheme combined with a fuzzy-logic-based approach. The proposed algorithm performed robustly under different scenarios with additional uncertainties, including $80 \%, 40 \%$, and 30\% total system inertia and mismatches in the primary/secondary control loops. Kerdphol et al. [45] proposed a model predictive control scheme and compared it to a fuzzy-logic controller for the case of additional load connections. Unlike the previous works, the studied microgrid has conceptual differences: a closed-loop turbine system, RES power generation from two complex wind farms, and minor differences in the transfer function describing the turbine and system inertia. Similar ideas were presented in Tamrakar et al. [72], but without modeling renewable energy disturbances. Magdy et al. [16] presented a PI controller optimized using particle swarm optimization and combined with a digital frequency protection system in scenarios of (dis)connecting loads and renewable energy sources.

In the following sections, we discuss the main features and constructive advantages and disadvantages of the most common algorithms for virtual inertia control, focusing on the load-frequency stability, implementation complexity, and performance against disturbances. We categorize the revised implementations into three groups: advanced, classical, and hybrid control as detailed in Figure 4. 


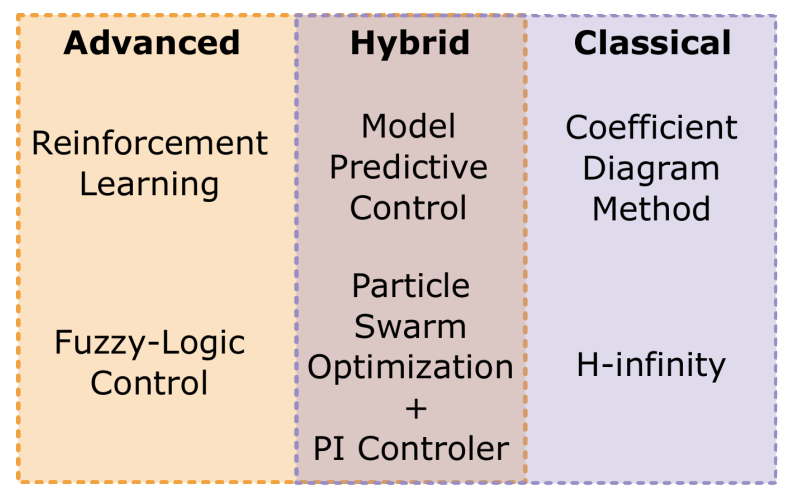

Figure 4. Classification of algorithms for virtual inertia control. PI-proportional integral.

\section{Classical Control Algorithms}

The major features of classical control algorithms are as follows:

- Classical optimization. The optimization is based on the reaction to disturbances, which are approximated by a transfer function or state-space representation. Usually, classical optimization are applied to slow processes [73].

- Simplicity. Classical algorithms have a simple control structure, which enables effective manual tuning and requires low computational power.

- High robustness. Classical algorithms can be highly robust, but require a specific design procedure.

\subsection{H-Infinity}

H-infinity, $H_{\infty}$, achieves the synthesis of an optimal controller by considering microgrid disturbances and uncertainties via state-space representation, which can provide high robustness and simple hardware realization. However, the main difficulty is the necessity of designing an accurate state-space description for tuning the controller [33,35]. Frequency control based on $H_{\infty}$ was used in [33,35,74-76]. The solution presented in [35] applies a linear fractional transformation in the optimal $H_{\infty}$ regulator design as the basis for modeling microgrid uncertainties $z$, such as system inertia $H$, damping properties $D$, and phased locked-loop (PLL) delays ( $\omega_{n}$ and $\zeta$ ).

$H_{\infty}$ optimization performs in offline mode and is more vulnerable to low-inertia nonlinearities than data-driven algorithms. At the same time, synthesis of the robust model by $H_{\infty}$ provides reliable frequency support. For example, Kerdphol et al. [33] implemented this method, which was successfully tested with $95 \%, 45 \%$, and $15 \%$ of the nominal system inertia and using two types of disturbances: (1) 10\% of step changes in load power demand and (2) mismatch in microgrid generation by increased time constant of the governor and time constant for the turbine. Kerdphol et al. [35] reported an $H_{\infty}$ controller tested with $100 \%$ and $10 \%$ system inertia in a scenario with $80 \%$ renewable energy penetration. However, the common limitation of the $H_{\infty}$ method is the notable peaks during (dis)connection of power plants. $H_{\infty}$ requires a detailed understanding of classical control theory and optimization, which does not require powerful hardware for operation. Nevertheless, the synthesized control model is a high-order transfer function and often requires order reduction $[33,35]$. The biggest difficulties with $H_{\infty}$ optimization are the procedure for developing an accurate state-space representation and the manual estimation of disturbances. The optimization based on application of the $H_{\infty}$ controller is summarized in Algorithm 1. 


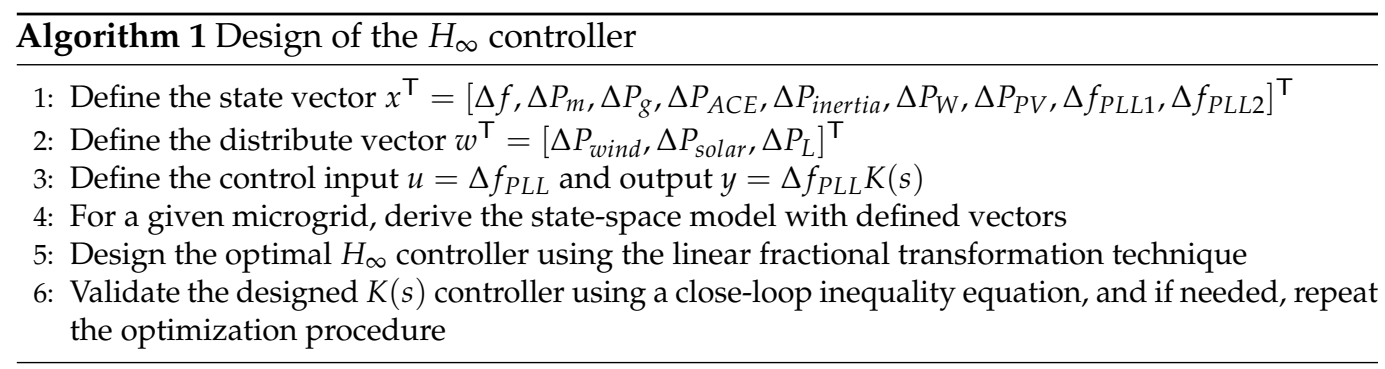

\subsection{Coefficient Diagram Method}

Controllers based on the coefficient diagram method (CDM) rely on an algebraic optimization approach through polynomial state-space representation and the RouthHurwitz stability criterion $[77,78]$, where the theoretical basis is constituted to satisfy the Lipatov-Sokolov stability criterion [79-82].

Similar to $H_{\infty}$, the optimization procedure is designed for offline mode. The implementation of a controller based on the CDM in Ali et al. [36] produced frequency stability in a range less than $\pm 0.1 \mathrm{~Hz}$ in a scenario with $100 \%$ inertia and two types of disturbances: (1) $10 \%$ step load perturbation and (2) random load demand. In contrast to $H_{\infty}$, it can mitigate peaks after the (dis)connection of renewable energy sources. However, the solution uses a two degrees of freedom system structure expressed as $N(s) / D(s)$, which is designed to track a limited number of disturbances. The main drawback of CDM controller synthesis is similar to $H_{\infty}$ : it relies on a good understanding of classical control theory optimization. However, it can be implemented using relatively simple hardware. In contrast to $H_{\infty}, \mathrm{CDM}$ optimization performs without requiring order reduction and uses the coefficient method instead of the Bode diagram [36,83]. However, the validation of synthesized control by Routh-Hurwitz or Lipatov-Sokolov stability criteria depends on the order of the synthesized control system $[36,81-83]$. The design procedure is summarized in Algorithm 2, which was adopted from the flowchart provided by [36].

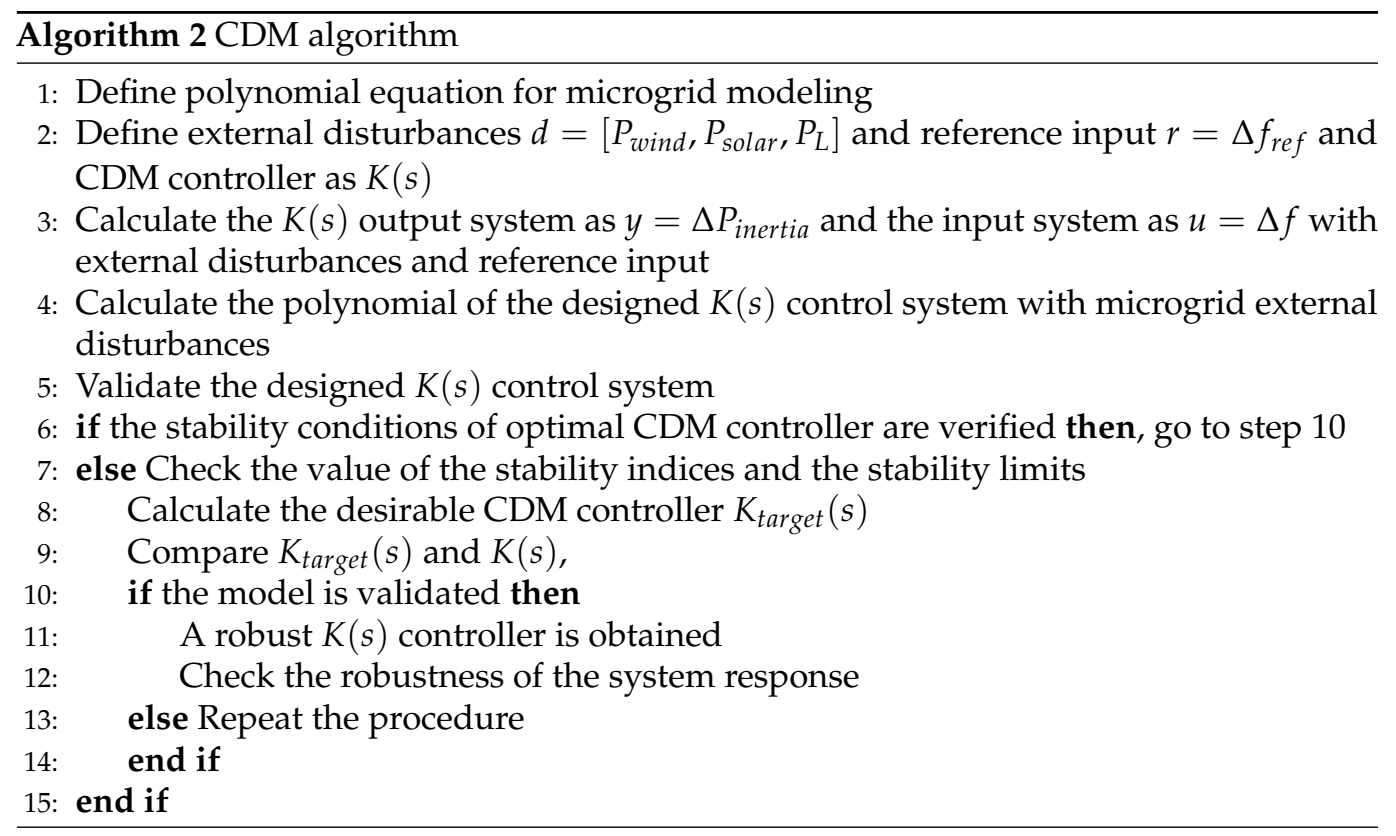

\section{Advanced Control Algorithms}

The major features of advanced control algorithms can be expressed as follows:

- Adaptation to uncertain conditions. Advanced control algorithms may provide adaptive reactions to disturbances that were not predicted. 
- Prediction-based optimization. Fast processes, such as electrical frequency variation, are easier to predict than postreaction. This principle gives additional advantages, because data-based optimization follows the events prediction model. The drawback of the approach is the necessity to design a memory buffer for data recording and further prediction-based tuning.

- Online learning. Data-driven optimization implies recorded data analysis of controlled processes. When conditions are changing radically, this approach provides a strategy for optimization of controller parameters in parallel with real-time control.

- Complexity. Advanced algorithms require a powerful computing system. The main benefit from complexity is effective multiloop control and adaptation to process dynamics.

\subsection{Reinforcement Learning-Based Controller}

Reinforcement learning (RL) is an agent-based and model-free machine learning algorithm [84]. The main approach of RL optimization is based on trial and error, which allows direct validation of the artificial neural network (ANN)-based controller with the control object and prediction of negative consequences [37,84-86]. The benefit of this method is mandatory data-driven optimization, which is naturally designed for online learning. In [37], RL was compared with $H_{\infty}$, producing slightly better performance in terms of frequency stability in scenarios with $100 \%, 80 \%$, and $40 \%$ inertia and connection of wind, solar, and thermal plants during the launch of industrial and residential loads, and $20 \%$ RES penetration. Since the algorithm uses a deep neural network, it requires strong computational hardware and is relatively complex for implementation. The method requires selection of an optimal action $a(t)^{*}$ at each step $s(t)$ and takes a long time. For RL, it is necessary to design a proper reward system and to choose the right training strategy, which may differ [37,87-89]. For example, in previous works [87,88], the RL optimization for frequency support was performed by approximated dynamic programming. In contrast, Skiparev et al. [37] used the deep deterministic policy gradient to train an RL-based controller for virtual inertia emulation. The optimization mechanism using the RL algorithm is summarized in Algorithm 3.

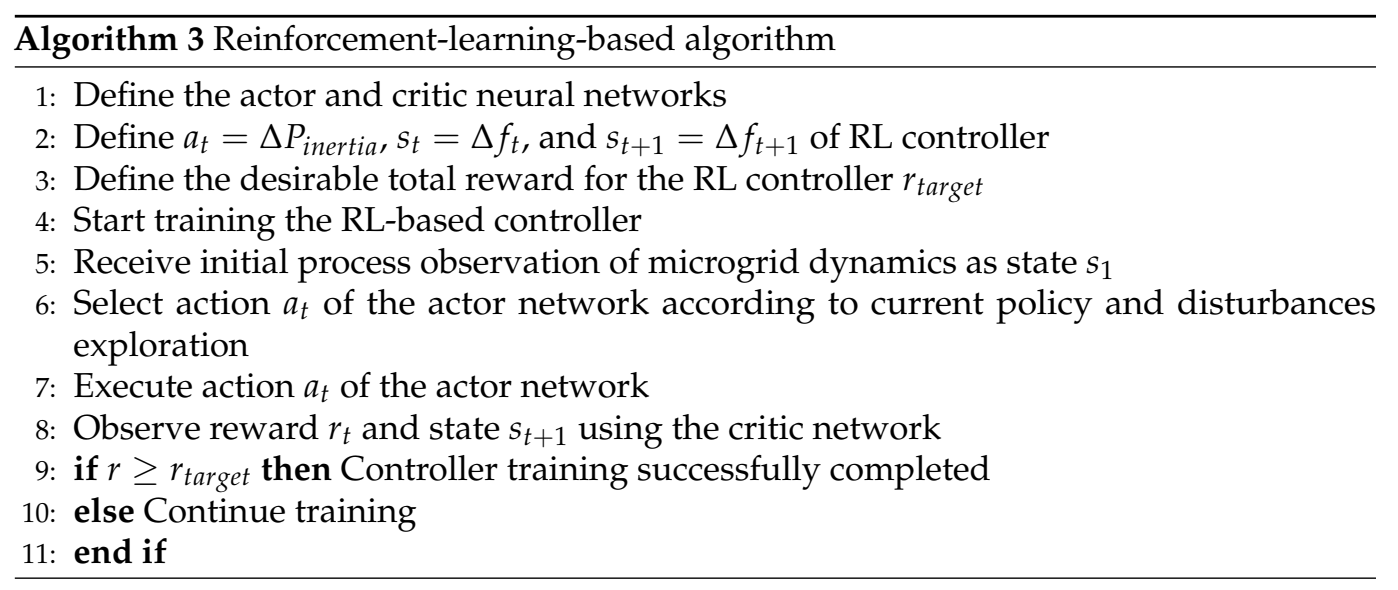

\subsection{Fuzzy Logic Controller}

Fuzzy logic controller design provides effective manual optimization compared with other advanced algorithms. Several examples of frequency regulation can be found in the literature [34,62,90-94]. Since fuzzy-logic-based controllers can be manually tuned, the data-driven approach is optional. Correct configuration of the controller can create a robust system. Kerdphol et al. [34] applied a standard fuzzy logic controller for virtual inertia control, which was capable most of the time of holding $\Delta f$ inside the $\pm 0.1 \mathrm{~Hz}$ band with $80 \%, 60 \%$, and $30 \%$ system inertia in scenarios with $20 \%$ and $80 \%$ RES penetration and mismatch in primary/secondary control loops. Controller design requires a good understanding of fuzzy rules design principles. In addition, the method requires powerful 
hardware for implementation. However, it uses fuzzy logic without an optimizer, which can be considered a drawback, since it requires the manual design of the optimal fuzzy rules $[92,95]$.

\section{Hybrid Control Algorithms}

Hybrid algorithms inherit features from both categories. Model predictive control (MPC) is an example of a controller that cannot be classified into either of the abovementioned categories. Optimization can be based on state-space representation [45] or input/output (I/O) relation approximated by the data-driven approach [96]. The PI controller optimized by particle swarm optimization (PSO) is another hybrid example, combining a simple controller with the data-driven approach [16].

\subsection{Evolutionary Optimization}

Particle swarm optimization is a popular evolutionary algorithm inspired by collective species behavior such as flocks of birds [97]; stochastic optimization should provide the best performance through searching for a global minima. The particle swarm strategy is a stochastic data-driven optimizer that enables online learning [16,56,98,99]. Magdy et al. [16] used PSO for optimal tuning of a PI controller via searching the global minima of a microgrid, which provided robust control with $100 \%, 80 \%$, and $30 \%$ system inertia. The performance of the optimal PI in Magdy et al. [16] showed relatively stable frequency support with $100 \%, 50 \%$, and $30 \%$ system inertia and with $57 \%$ RES penetration. In contrast with other solutions, Magdy et al. [16] applied a dynamic model of a microgrid with digital protection, which provided additional frequency stability. PI/PID is a widely used controller in the power industry due to its simple construction [100-102]. However, the PSO algorithm is a self-learning optimizer, which is more complex for implementation. To produce an optimally tuned PI controller, the optimizer has to consider the state-space dynamic modeling of microgrid uncertainties, which requires a relatively long time to find optimal settings. The PSO procedure is summarized in Algorithm 4, adopted from [16].

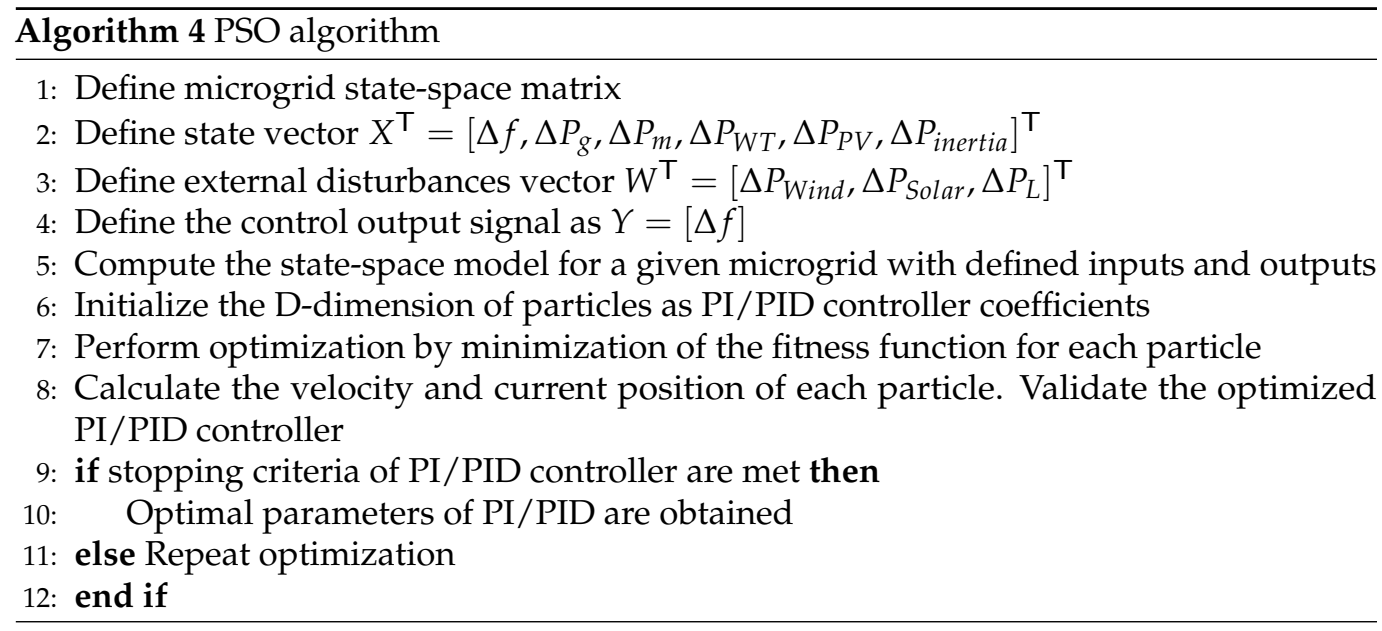

\subsection{Model Predictive Control}

The model predictive controller (MPC) requires the development of a robust prediction model based on a detailed representation of the process dynamics via collected data $[45,103,104]$. As a hybrid algorithm, the MPC can be implemented with data-driven [105] or finite-time-horizon [46,106] optimization approaches. Kerdphol et al. [45] applied finite impulse response optimization for model prediction based on the virtual inertia emulation with microgrid state-space representation.

Regarding optimization, MPC can provide real-time learning through data-driven and finite-horizon approaches. According to Kerdphol et al. [45], MPC performance is higher than that of the fuzzy-logic-based controller, and may provide better $\Delta f$ stability 
during (1) (dis)connection of RES power, (2) sudden load change, and (3) mismatch in the main thermal generation scenarios with $100 \%, 50 \%$, and $25 \%$ system inertia and $34 \%$ RES penetration. Implementation of the model-prediction-based controller depends on the type of prediction model. The controller requires the calculation of each time sample and heavily depends on the designed model used in the predictions of microgrid disturbances [45,72]. Specifically, Kerdphol et al. [45] used the finite impulse response, which considers each sampling instant in the prediction of microgrid disturbances. The general concept of MPC optimization is summarized in Algorithm 5.

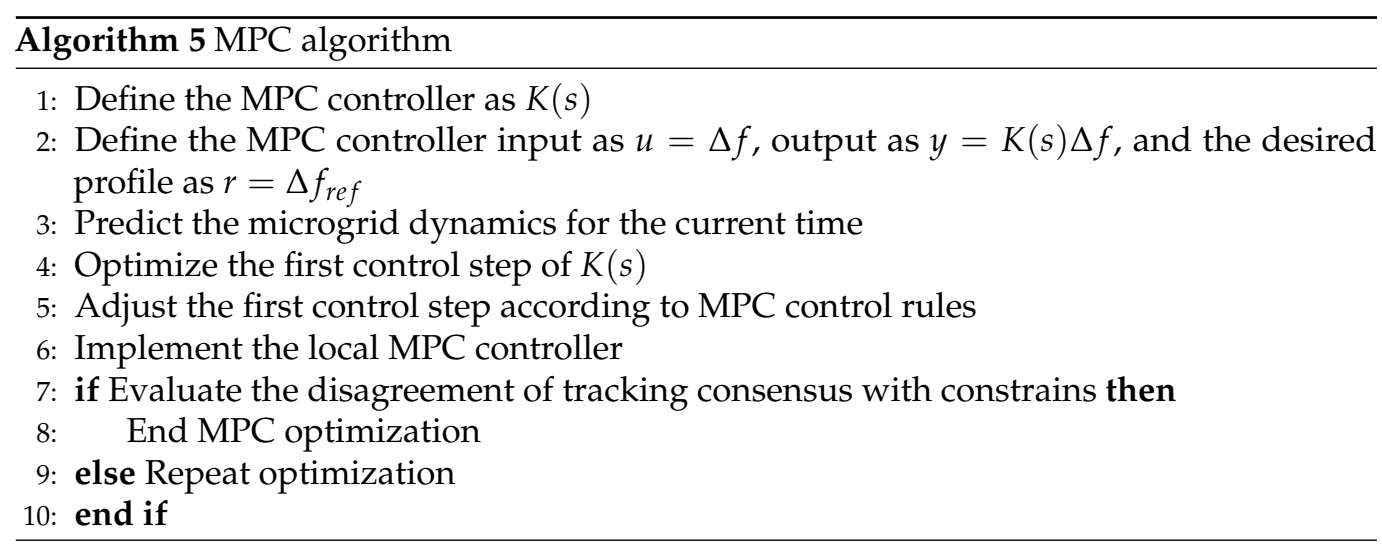

\section{Recent Directions and Trends}

One goal of this study was to highlight the popularity of various control methods for virtual inertia emulation reflected in the recent literature. Such trends are explored in this section based on the contextual analysis of additional virtual inertia control. Based on this analysis, we explain the motivation for the choice of several optimal control methods and try to better understand why and when the reviewed methods are most efficient. Special attention is paid to the analysis of relevant keywords describing each method and application area. The fuzzy logic controller, model predictive control, coefficient diagram method, and $H$-infinity methods are well-defined by their names. However, reinforcementlearning and evolution algorithms are often defined by a specific strategy. Therefore, we used several of the most common types of these optimizations during our literature search. The keywords we used for the control methods are summarized in Table 3. The search was also restricted to the title, abstract, and keywords fields.

Table 3. Search expressions that were used in the literature search.

\begin{tabular}{lcc}
\hline Primary Expression & Secondary Expression & Third Expression \\
\hline "virtual inertia control" & "FLC OR Fuzzy Logic Controller" \\
"MPC OR Model predictive \\
control" \\
"PI/PID" \\
"EA OR GA OR Evolution \\
algorithms OR Genetic algorithms \\
"CDM OR Coefficient diagram \\
method" \\
"Ho OR H-infinity" \\
"PSO OR Particle swarm \\
optimization" \\
"RL OR Reinforcement learning " \\
\hline
\end{tabular}


Figure 5 depicts the rising trend in publications on virtual inertia control over an 11-year period. The Scopus database produced 404 papers and IEEE Xplore produced 239 papers.

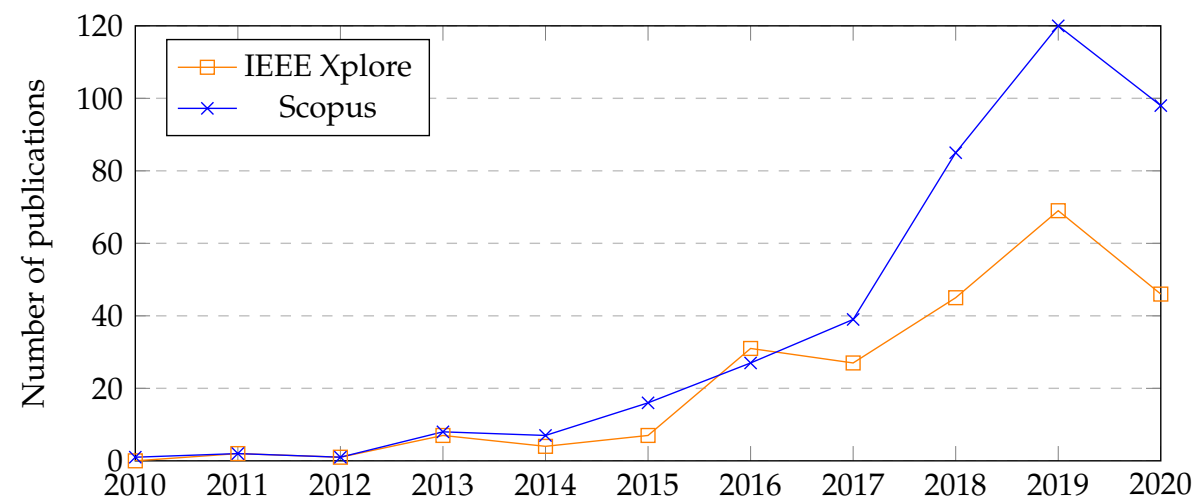

Figure 5. Yearly number of publications in the period from 2010 to 2020 on virtual inertia control.

The frequency-support-related algorithms mostly continued the rising trend, as detailed in Figure 6. To provide a more in-depth analysis, we selected several algorithms commonly used in frequency-control applications. Fuzzy logic and PI/PID appeared to be the most popular control algorithms. Publications indicate the stable interest in usage of PID controller, which can be further equipped with an additional optimization loop based on data-driven algorithms and/or combined with advanced controllers [16,62,99,107,108]. Due to the natural ability in finding global minima, evolution algorithms (e.g., PSO, firefly, and bat) are mostly combined with the fuzzy logic controller (FLC) and/or PID [16,62,99] as one of the most frequently used hybrid algorithms of the existing control loops. Model predictive controllers gained similar attention; in recent years, they have become the most popular. One notable rise was found in the usage of the reinforcement-learning-based strategies, which may become even more popular in the next years due to their ability to perform effective study based on interactions with the environment $[37,85,88]$. Therefore, we think that the data-driven algorithms will attract more attention in the coming years due to the growing prevalence of data mining and cloud technologies.

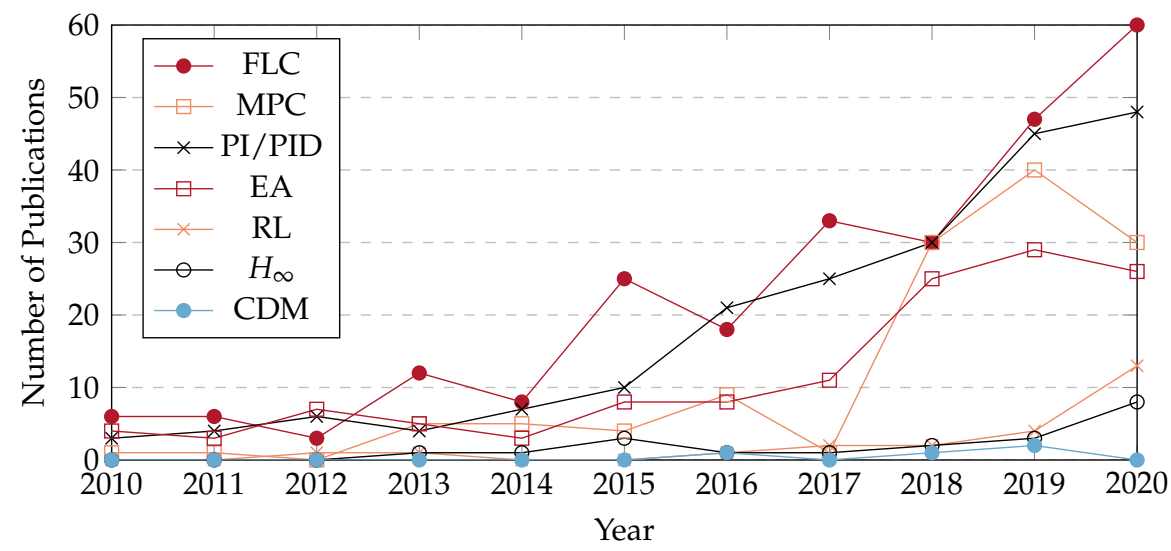

Figure 6. Trends in the frequency-support algorithms in microgrids. FLC-fuzzy logic controller, MPC - model predictive control, EA—evolution algorithm, RL-reinforcement learning, $H_{\infty}-\mathrm{H}-$ infinity, CDM-coefficient diagram method.

Figure 7 depicts the search results for the specific technologies used for frequency regulation in microgrids. Energy storage appears to be the most widely used technology. Virtual synchronous generators, virtual inertia, and phase locked-loop have small numbers of publications, since each technology related to synthetic inertia generation is individual 
and requires specific design and case studies. Notably, many possibilities exist for research into VSG/VI-related applications [12,22].

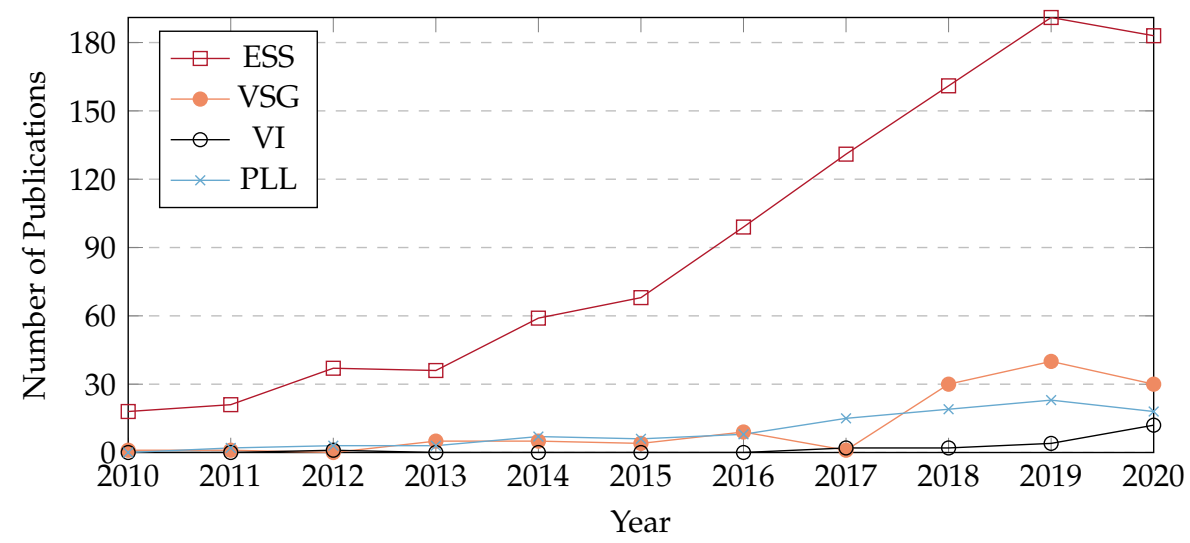

Figure 7. Trends in frequency-control technologies in microgrids. ESS-energy storage system, VSG—virtual synchronous generator, VI-virtual inertia, PLL—phased locked-loop.

Based on analysis of the above trends, it is reasonable to conjecture that in the coming years, the virtual inertia problem will remain in the focus of the community. The isolated microgrid, as a part of the general power grid, faces several important challenges such as active and reactive power balance, power losses in transmission lines, grid frequency outmatching, power production/consumption balance, among others [109]. Most microgrids use simplified models of domestic loads, power plants, and energy storage systems. The European Commission reported the potential research challenges in the renewable energy area in the period of 2021-2027:

- Integrated local energy systems, microgrids, and modular solutions [110-113];

- Cross-border cooperation in transmission grids [110,114-117];

- $\quad$ Electrical transport (cars, trucks, ships, etc.) [110,118-120];

- $\quad$ Effective energy management in domestic appliances (HVAC, boilers) by demand-side management technologies [110,113,115,121,122];

- $\quad$ Solutions for the integration of energy systems and coupling of different energy vectors, networks, and infrastructures in the context of a digitalized, green, and cybersecure energy system [110,113,123].

According to the REN21 report, 63\% of world experts agree that by 2050, power generation will focus on centralized or decentralized renewable energy [119] and 71\% agree that the transition to $100 \%$ renewable energy on a global level is feasible and realistic [119]. In addition, most experts agree that renewable energy should provide at least $32 \%$ of the EU energy consumption by 2030 [2,119]. Hence, there is a clear need for continuing the research on and adoption of various solutions, supporting the integration of renewable energy sources; microgrids will most likely play a key role in achieving these goals.

\section{Conclusions}

Here, we reviewed recent works related to virtual inertia control methods designed to solve the frequency regulation problem in islanded microgrids, with an attempt to better understand the unique characteristics, common uses, and mathematical foundations of the most popular control methods. The control techniques on which we chose to focus were selected following an in-depth content analysis of various sources from the main databases, as detailed in Section 6. This analysis revealed interesting trends in the current research, and may help to understand why certain control methods are more efficient in different circumstances (Table 4), and which control strategies will gain popularity in the coming years. 
Table 4. Comparison of virtual inertia control algorithms: advantages, drawbacks, and quality criteria.

\begin{tabular}{|c|c|c|c|c|c|c|c|c|}
\hline & Hand. App. & $\begin{array}{l}\text { Online/ } \\
\text { Offline }\end{array}$ & Advantages & Drawbacks & $\begin{array}{c}\text { Computational } \\
\text { Complexity }\end{array}$ & Robustness & $\begin{array}{c}\text { Optimization } \\
\text { Complexity }\end{array}$ & Refs. \\
\hline \multirow[t]{2}{*}{ 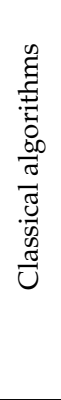 } & $\begin{array}{l}\text { Robust H- } \\
\text { infinity }\end{array}$ & Offline & $\begin{array}{l}\text { - Robust frequency } \\
\text { control } \\
\text { - Strong overshoot } \\
\text { minimization }\end{array}$ & $\begin{array}{l}\text { - Significant peaks } \\
\text { during connec- } \\
\text { tion disturbances } \\
\text { - Need for order } \\
\text { reduction } \\
\text { - Limited robust- } \\
\text { ness }\end{array}$ & Medium & High & Medium & $\begin{array}{c}{[36,74,75,124-} \\
126]\end{array}$ \\
\hline & $\begin{array}{l}\text { Coefficient } \\
\text { diagram } \\
\text { method }\end{array}$ & Offline & $\begin{array}{l}\text { - Higher robust- } \\
\text { ness } \\
\text { - No need for } \\
\text { order reduction }\end{array}$ & $\begin{array}{l}\text { - Limited robust- } \\
\text { ness }\end{array}$ & Medium & High & Medium & {$[36,81,83,127]$} \\
\hline \multirow{2}{*}{ 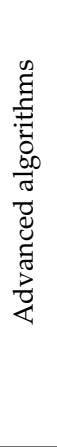 } & $\begin{array}{l}\text { Fuzzy-logic- } \\
\text { based con- } \\
\text { troller }\end{array}$ & Online & - Flexible reaction & $\begin{array}{l}\text { - Limited by fuzzy } \\
\text { rules adaptation } \\
\text { - Manual optimiza- } \\
\text { tion } \\
\text { - Long compu- } \\
\text { tational time }\end{array}$ & High & High & High & {$[16,34,45,128]$} \\
\hline & $\begin{array}{l}\text { Reinforcement- } \\
\text { learning- } \\
\text { based } \\
\text { controller }\end{array}$ & Online & $\begin{array}{l}\text { - Reward learning } \\
\text { system } \\
\text { - Advanced feed- } \\
\text { back from system } \\
\text { - High robustness }\end{array}$ & $\begin{array}{l}\text { - Available sample } \\
\text { data are needed } \\
\text { - Specific to the re- } \\
\text { ward/punishment } \\
\text { optimization }\end{array}$ & Very High & High & Very High & $\begin{array}{l}{[37,85,87,88,} \\
129]\end{array}$ \\
\hline \multirow{2}{*}{ 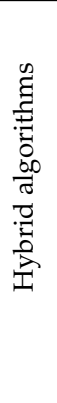 } & $\begin{array}{l}\text { PI/PID and } \\
\text { particle } \\
\text { swarm op- } \\
\text { timization }\end{array}$ & Online & $\begin{array}{l}\text { - Low numeric } \\
\text { complexity } \\
\text { - Simple controller }\end{array}$ & $\begin{array}{l}\text { - Convergence to } \\
\text { global optimal } \\
\text { solution is not } \\
\text { guaranteed } \\
\text { - Limited robust- } \\
\text { ness }\end{array}$ & Low & Low & Low & {$[16,56,98]$} \\
\hline & $\begin{array}{l}\text { Model predic- } \\
\text { tive control }\end{array}$ & Online & $\begin{array}{l}\text { - High robustness } \\
\text { - Fast reaction } \\
\text { based on predic- } \\
\text { tion } \\
\text { - Fast optimization }\end{array}$ & $\begin{array}{l}\text { - Need data re- } \\
\text { served for predic- } \\
\text { tion model } \\
\text { - Complex opti- } \\
\text { mization }\end{array}$ & High & High & High & $\begin{array}{c}{[45,46,70,72} \\
106,130]\end{array}$ \\
\hline
\end{tabular}

For instance, the data show that evolutionary algorithms methods are widely used for tuned PI/PID controllers probably since this enables the analysis of stochastic scenarios with nonlinear constraints. However, evolutionary algorithms may converge to local minima and are therefore not suitable for every application. In such cases, classical control methods seem to be the natural choice since they provide simple and effective solutions to the virtual inertia problems whenever grid dynamics are well-defined. If there is uncertainty in the grid dynamic and nonlinear constraints, fuzzy-logic-based controllers are used extensively, although they are limited to specific and manually defined rules; in cases with a large number of rules, the needed resources increase significantly. The controllers based on the coefficient diagram method principle seem to be the least popular method, maybe due to their limitation of tracking only a limited number of disturbances. Artificial neural networks are also increasing in use due to the increasing amounts of available data; specifically, reinforcement-learning methods are commonly used for solving complex problems when a fully satisfactory algorithm is lacking. In our opinion, these trends may change in the near future due to global initiatives related to the integration of electric vehicles into microgrids and due to the continuing integration of renewable energy sources and beyond-the-meter technologies, which may lead to more available data and thus favor the use of new and more efficient controllers with a focus on datadriven approaches.

Concerning future research, since microgrids are increasingly decentralized and less regulated by governments, it is often impractical to study them from the perspective 
of one single entity with unlimited information and control span. Therefore, the recent increasing trend in studies of virtual inertia control for isolated microgrids will likely continue. Whereas classic control techniques are still mainly the focus of the community, the wide adoption and integration of technological innovations such as the Internet of things (IoT), cloud technologies, and data processing powers will likely start shifting the main attention toward data-driven control techniques in the coming years. Another topic of interest may be combining virtual inertia control with suitable energy storage as a supportive technological solution in isolated microgrids. To answer this challenge, the development of new optimal control methods can be considered a possible avenue for future research.

Author Contributions: Conceptualization, V.S., R.M. and J.B.; methodology, V.S. and R.M.; software, V.S.; formal analysis, V.S.; writing—original draft preparation, V.S., R.M. and N.R.C.; writing—review and editing, J.B., Y.L., R.M and E.P.; visualization, V.S. and J.B.; supervision, J.B. and E.P.; funding acquisition, E.P. All authors have read and agreed to the published version of the manuscript.

Funding: V. Skiparev was partially conducted within the ICT programme project, which was supported by the European Union through the European Social Fund. V. Skiparev and E. Petlenkov were partly supported by the Estonian Research Council grant PRG658. Y. Levron was partly supported by Israel Science Foundation grant No. 1227/18.

Conflicts of Interest: The authors declare no conflict of interest.

\section{Abbreviations}

The following abbreviations are used in this manuscript:

$\begin{array}{ll}\text { ANN } & \text { Artificial neural network } \\ \text { EA } & \text { Evolution algorithms } \\ \text { ESS } & \text { Energy storage system } \\ \text { CDM } & \text { Coefficient diagram method } \\ \text { FLC } & \text { Fuzzy logic controller } \\ \text { GRC } & \text { Generator rate constraint } \\ \text { HVAC } & \text { Heating, ventilation, and air conditioning } \\ \text { LFC } & \text { Load-frequency control } \\ \text { MPC } & \text { Model predictive control } \\ \text { PCC } & \text { Point of common coupling } \\ \text { PID } & \text { Proportional-integral-derivative } \\ \text { PLL } & \text { Phased locked-loop } \\ \text { PSO } & \text { Particle swarm optimization } \\ \text { RL } & \text { Reinforcement learning } \\ \text { RES } & \text { Renewable energy sources } \\ \text { RoCoF } & \text { Rate of change of frequency } \\ \text { VI } & \text { Virtual inertia } \\ \text { VSG } & \text { Virtual synchronous generator }\end{array}$

\section{References}

1. Ulbig, A.; Borsche, T.S.; Andersson, G. Impact of low rotational inertia on power system stability and operation. IFAC Proc. Vol. 2014, 47, 7290-7297. [CrossRef]

2. Kroposki, B.; Johnson, B.; Zhang, Y.; Gevorgian, V.; Denholm, P.; Hodge, B.M.; Hannegan, B. Achieving a $100 \%$ renewable grid: Operating electric power systems with extremely high levels of variable renewable energy. IEEE Power Energy Mag. 2017, 15, 61-73. [CrossRef]

3. Milano, F.; Dörfler, F.; Hug, G.; Hill, D.J.; Verbic, G. Foundations and Challenges of Low-Inertia Systems (Invited Paper). In Proceedings of the 2018 Power Systems Computation Conference (PSCC), Dublin, Ireland, 11-15 June 2018. [CrossRef]

4. Kumar, D.; Mukherjee, B.K.; Mathur, H.D.; Siguerdidjane, H.; Bhanot, S. Forecast-based modeling and robust frequency control of standalone microgrids considering high penetration of renewable sources. Int. Trans. Electr. Energy Syst. 2020, 31. [CrossRef]

5. Boicea, V.A. Energy Storage Technologies: The Past and the Present. Proc. IEEE 2014, 102, 1777-1794. [CrossRef] 
6. Groß, D.; Bolognani, S.; Poolla, B.K.; Dörfler, F. Increasing the Resilience of Low-inertia Power Systems by Virtual Inertia and Damping. In Proceedings of the 10th Bulk Power Systems Dynamics and Control Symposium (IREP 2017), Espinho, Portugal, 27 August-1 September 2017. [CrossRef]

7. Vorobev, P.; Huang, P.H.; Hosani, M.A.; Kirtley, J.L.; Turitsyn, K. A framework for development of universal rules for microgrids stability and control. In Proceedings of the 2017 IEEE 56th Annual Conference on Decision and Control (CDC), Melbourne, VIC, Australia, 12-15 December 2017. [CrossRef]

8. Groß, D.; Dörfler, F. On the steady-state behavior of low-inertia power systems. IFAC-PapersOnLine 2017, 50, 10735-10741. [CrossRef]

9. Ojo, Y.; Watson, J.; Lestas, I. A Review of Reduced-Order Models for Microgrids: Simplifications vs Accuracy. arXiv 2020, arXiv:2003.04923.

10. Abubakr, H.; Mohamed, T.H.; Hussein, M.M.; Guerrero, J.M.; Agundis-Tinajero, G. Adaptive frequency regulation strategy in multi-area microgrids including renewable energy and electric vehicles supported by virtual inertia. Int. J. Electr. Power Energy Syst. 2021, 129, 106814. [CrossRef]

11. Kerdphol, T.; Rahman, F.S.; Watanabe, M.; Mitani, Y. Virtual Inertia Synthesis and Control; Springer International Publishing: Cham, Switzerland, 2021. [CrossRef]

12. Tamrakar, U.; Shrestha, D.; Maharjan, M.; Bhattarai, B.; Hansen, T.; Tonkoski, R. Virtual Inertia: Current Trends and Future Directions. Appl. Sci. 2017, 7, 654. [CrossRef]

13. Moon, H.J.; Chang, J.W.; Lee, S.Y.; Moon, S.I. Autonomous active power management in isolated microgrid based on proportional and droop control. Energy Procedia 2018, 153, 48-55. [CrossRef]

14. Zhu, J.; Zheng, Y.; Wang, Y.; Yuan, Y. Isolated Microgrid Capacity Configuration Considering Economic Risk of Customer Interruption. In Proceedings of the 2019 IEEE Innovative Smart Grid Technologie -Asia (ISGT Asia), Chengdu, China, 21-24 May 2019. [CrossRef]

15. Yap, K.Y.; Sarimuthu, C.R.; Lim, J.M.Y. Virtual Inertia-Based Inverters for Mitigating Frequency Instability in Grid-Connected Renewable Energy System: A Review. Appl. Sci. 2019, 9, 5300. [CrossRef]

16. Magdy, G.; Shabib, G.; Elbaset, A.A.; Mitani, Y. A Novel Coordination Scheme of Virtual Inertia Control and Digital Protection for Microgrid Dynamic Security Considering High Renewable Energy Penetration. IET Renew. Power Gener. 2019, 13, 462-474. [CrossRef]

17. Padmawansa, N.U.; Arachchige, L.N.W. Improving Transient Stability of an Islanded Microgrid Using PV Based Virtual Synchronous Machines. In Proceedings of the 2020 Moratuwa Engineering Research Conference (MERCon), Moratuwa, Sri Lanka, 28-30 July 2020. [CrossRef]

18. Vasquez, J.C.; Miret, J.M.G.J.; Castilla, M.; de Vicuña, L.G. Hierarchical Control of Intelligent Microgrids. IEEE Ind. Electron. Mag. 2010, 4, 23-29. [CrossRef]

19. Akinyele, D.; Belikov, J.; Levron, Y. Challenges of Microgrids in Remote Communities: A STEEP Model Application. Energies 2018, 2, 432. [CrossRef]

20. Katiraei, F.; Iravani, R.; Hatziargyriou, N.; Dimeas, A. Microgrids management. IEEE Power Energy Mag. 2008, 6, 54-65. [CrossRef]

21. Singh, D.; Seethalekshmi, K. A Review on Various Virtual Inertia Techniques for Distributed Generation. In Proceedings of the 2020 International Conference on Electrical and Electronics Engineering (ICE3), Gorakhpur, India, 14-15 February 2020. [CrossRef]

22. Fernández-Guillamón, A.; Gómez-Lázaro, E.; Muljadi, E.; Molina-García, Á. Power systems with high renewable energy sources: A review of inertia and frequency control strategies over time. Renew. Sustain. Energy Rev. 2019, 115, 109369. [CrossRef]

23. Hiskens, I.A.; Fleming, E.M. Control of inverter-connected sources in autonomous microgrids. In Proceedings of the 2008 American Control Conference, Seattle, WA, USA, 11-13 June 2008. [CrossRef]

24. Schiffer, J.; Zonetti, D.; Ortega, R.; Stanković, A.M.; Sezi, T.; Raisch, J. A survey on modeling of microgrids-From fundamental physics to phasors and voltage sources. Automatica 2016, 74, 135-150. [CrossRef]

25. Guo, F.; Wang, L.; Wen, C.; Zhang, D.; Xu, Q. Distributed Voltage Restoration and Current Sharing Control in Islanded DC Microgrid Systems Without Continuous Communication. IEEE Trans. Ind. Electron. 2020, 67, 3043-3053. [CrossRef]

26. Jung, S.; Yoon, Y.T.; Huh, J.H. An Efficient Micro Grid Optimization Theory. Mathematics 2020, 8, 560. [CrossRef]

27. Mendieta, W.; Canizares, C.A. Primary Frequency Control in Isolated Microgrids Using Thermostatically Controllable Loads. IEEE Trans. Smart Grid 2021, 12, 93-105. [CrossRef]

28. Van, T.V.; Visscher, K.; Diaz, J.; Karapanos, V.; Woyte, A.; Albu, M.; Bozelie, J.; Loix, T.; Federenciuc, D. Virtual synchronous generator: An element of future grids. In Proceedings of the 2010 IEEE PES Innovative Smart Grid Technologies Conference Europe (ISGT Europe), Gothenburg, Sweden, 11-13 October 2010. [CrossRef]

29. Zhong, Q.C.; Weiss, G. Synchronverters: Inverters That Mimic Synchronous Generators. IEEE Trans. Ind. Electron. 2011, 58, 1259-1267. [CrossRef]

30. Bevrani, H.; Ise, T.; Miura, Y. Virtual synchronous generators: A survey and new perspectives. Int. J. Electr. Power Energy Syst. 2014, 54, 244-254. [CrossRef]

31. Zhong, Q.C.; Konstantopoulos, G.C.; Ren, B.; Krstic, M. Improved Synchronverters with Bounded Frequency and Voltage for Smart Grid Integration. IEEE Trans. Smart Grid 2018, 9, 786-796. [CrossRef] 
32. Curi, S.; Gross, D.; Dorfler, F. Control of low-inertia power grids: A model reduction approach. In Proceedings of the 2017 IEEE 56th Annual Conference on Decision and Control (CDC), Melbourne, VIC, Australia, 12-15 December 2017. [CrossRef]

33. Kerdphol, T.; Rahman, F.S.; Mitani, Y.; Watanabe, M.; Küfeoğlu, S. Robust virtual inertia control of an islanded microgrid considering high penetration of renewable energy. IEEE Access 2018, 6, 625-636. [CrossRef]

34. Kerdphol, T.; Watanabe, M.; Hongesombut, K.; Mitani, Y. Self-adaptive virtual inertia control-based Fuzzy logic to improve frequency stability of microgrid with high renewable penetration. IEEE Access 2019, 7, 76071-76083. [CrossRef]

35. Kerdphol, T.; Rahman, F.S.; Watanabe, M.; Mitani, Y. Robust virtual inertia control of a low inertia microgrid considering frequency measurement effects. IEEE Access 2019, 7, 57550-57560. [CrossRef]

36. Ali, H.; Magdy, G.; Li, B.; Shabib, G.; Elbaset, A.A.; Xu, D.; Mitani, Y. A new frequency control strategy in an islanded microgrid using virtual inertia control-based coefficient diagram method. IEEE Access 2019, 7, 16979-16990. [CrossRef]

37. Skiparev, V.; Belikov, J.; Petlenkov, E. Reinforcement learning based approach for virtual inertia control in microgrids with renewable energy sources. In Proceedings of the IEEE PES Innovative Smart Grid Technologies Europe (ISGT-Europe), The Hague, The Netherlands, 26-28 October 2020.

38. Rosewater, D.M.; Copp, D.A.; Nguyen, T.A.; Byrne, R.H.; Santoso, S. Battery Energy Storage Models for Optimal Control. IEEE Access 2019, 7, 178357-178391. [CrossRef]

39. Naderipour, A.; Abdul-Malek, Z.; Hajivand, M.; Seifabad, Z.M.; Farsi, M.A.; Nowdeh, S.A.; Davoudkhani, I.F. Spotted hyena optimizer algorithm for capacitor allocation in radial distribution system with distributed generation and microgrid operation considering different load types. Sci. Rep. 2021, 11. [CrossRef]

40. Ummels, B.C.; Gibescu, M.; Pelgrum, E.; Kling, W.L.; Brand, A.J. Impacts of Wind Power on Thermal Generation Unit Commitment and Dispatch. IEEE Trans. Energy Convers. 2007, 22, 44-51. [CrossRef]

41. Bevrani, H. Robust Power System Frequency Control, 2nd ed.; Springer: Berlin, Germany, 2014.

42. Torres, L.M.A.; Lopes, L.A.C.; Morán, T.L.A.; Espinoza, C.J.R. Self-Tuning Virtual Synchronous Machine: A Control Strategy for Energy Storage Systems to Support Dynamic Frequency Control. IEEE Trans. Energy Convers. 2014, 29, 833-840. [CrossRef]

43. Kundur, P. Power System Stability and Control; MCGRAW HILL BOOK CO.: New York, NY, USA, 1994.

44. RG-CE System Protection \& Dynamics Sub Group. Rate of Change of Frequency (RoCoF) with Stand Capability; Technical Report; ENTSO-E: Brussels, Belgium, 2018.

45. Kerdphol, T.; Rahman, F.; Mitani, Y.; Hongesombut, K.; Küfeoğlu, S. Virtual inertia control-based model predictive control for microgrid frequency stabilization considering high renewable energy integration. Sustainability 2017, 9, 773. [CrossRef]

46. Sockeel, N.; Gafford, J.; Papari, B.; Mazzola, M. Virtual inertia emulator-based model predictive control for grid frequency regulation considering high penetration of inverter-based energy storage system. IEEE Trans. Sustain. Energy 2020, 11, 2932-2939. [CrossRef]

47. Beck, H.P.; Hesse, R. Virtual synchronous machine. In Proceedings of the International Conference on Electrical Power Quality and Utilisation, Barcelona, Spain, 9-11 October 2007. [CrossRef]

48. Guggilam, S.S.; Zhao, C.; Dall'Anese, E.; Chen, Y.C.; Dhople, S.V. Engineering inertial and primary-frequency response for distributed energy resources. In Proceedings of the 2017 IEEE 56th Annual Conference on Decision and Control (CDC), Melbourne, VIC, Australia, 12-15 December 2017. [CrossRef]

49. Díaz-González, F.; Sumper, A.; Gomis-Bellmunt, O.; Villafáfila-Robles, R. A review of energy storage technologies for wind power applications. Renew. Sustain. Energy Rev. 2012, 16, 2154-2171. [CrossRef]

50. Molina, M.G. Grid Energy Storage Systems; Wiley: New York, NY, USA, 2019; pp. 495-583. [CrossRef]

51. Kunisch, H.J.; Kramer, K.G.; Dominik, H. Battery Energy Storage Another Option for Load-Frequency-Control and Instantaneous Reserve. IEEE Trans. Energy Convers. 1986, EC-1, 41-46. [CrossRef]

52. Ribeiro, P.F.; Crow, M.L. Energy storage systems for advanced power applications. Proc. IEEE 2001, 89, 1744-1756. [CrossRef]

53. Zeng, J.; Zhang, B.; Mao, C.; Wang, Y. Use of battery energy storage system to improve the power quality and stabilty of wind farms. In Proceedings of the 2006 International Conference on Power System Technology, Chongqing, China, 22-26 October 2006. [CrossRef]

54. Oudalov, A.; Chartouni, D.; Ohler, C. Optimizing a Battery Energy Storage System for Primary Frequency Control. IEEE Trans. Power Syst. 2007, 22, 1259-1266. [CrossRef]

55. Bazargan, D.; Filizadeh, S.; Gole, A. Stability analysis of converter-connected battery energy storage systems in the grid. IEEE Trans. Sustain. Energy 2014, 5, 1204-1212. [CrossRef]

56. Kerdphol, T.; Qudaih, Y.; Mitani, Y. Optimum battery energy storage system using PSO considering dynamic demand response for microgrids. Int. J. Electr. Power Energy Syst. 2016, 83, 58-66. [CrossRef]

57. Toma, L.; Sanduleac, M.; Baltac, S.A.; Arrigo, F.; Mazza, A.; Bompard, E.; Musa, A.; Monti, A. On the virtual inertia provision by BESS in low inertia power systems. In Proceedings of the 2018 IEEE International Energy Conference (ENERGYCON), Limassol, Cyprus, 3-7 June 2018. [CrossRef]

58. Feng, X. Dynamic balancing for low inertia power systems. In Proceedings of the 2013 IEEE Power \& Energy Society General Meeting, Vancouver, BC, Canada, 21-25 July 2013. [CrossRef]

59. Vandoorn, T.L.; Vasquez, J.C.; Kooning, J.D.; Guerrero, J.M.; Vandevelde, L. Microgrids: Hierarchical Control and an Overview of the Control and Reserve Management Strategies. IEEE Ind. Electron. Mag. 2013, 7, 42-55. [CrossRef] 
60. Dragicevic, T.; Wu, D.; Shafiee, Q.; Meng, L. Distributed and decentralized control architectures for converter-interfaced microgrids. Chin. J. Electr. Eng. 2017, 3, 41-52. [CrossRef]

61. Wu, Y.; Wu, Y.; Guerrero, J.M.; Vasquez, J.C.; Li, J. AC Microgrid Small-Signal Modeling: Hierarchical Control Structure Challenges and Solutions. IEEE Electrif. Mag. 2019, 7, 81-88. [CrossRef]

62. Bevrani, H.; Habibi, F.; Babahajyani, P.; Watanabe, M.; Mitani, Y. Intelligent Frequency Control in an AC Microgrid: Online PSO-Based Fuzzy Tuning Approach. IEEE Trans. Smart Grid 2012, 3, 1935-1944. [CrossRef]

63. Corno, M.; Formentin, S.; Savaresi, S.M. Data-Driven Online Speed Optimization in Autonomous Sailboats. IEEE Trans. Intell. Transp. Syst. 2016, 17, 762-771. [CrossRef]

64. ISO. ISO 8528-5:2005: Reciprocating Internal Combustion Engine Driven Alternating Current Generating Sets-Part 5: Generating Set; Technical Report; International Organization for Standardization: Geneva, Switzerland, 2005.

65. ISO. ISO 8528-5:2018 Reciprocating Internal Combustion Engine Driven Alternating Current Generating Sets—Part 5: Generating Sets; Technical Report; International Organization for Standardization (ISO): Geneva, Switzerland, 2018.

66. ENTSO-E. Continental Europe Significant Frequency Deviations; Technical Report; ENTSO-E: Brussels, Belgium, 2019.

67. Wang, C.; Mi, Y.; Fu, Y.; Wang, P. Frequency Control of an Isolated Micro-Grid Using Double Sliding Mode Controllers and Disturbance Observer. IEEE Trans. Smart Grid 2018, 9, 923-930. [CrossRef]

68. Ganjian-Aboukheili, M.; Shahabi, M.; Shafiee, Q.; Guerrero, J.M. Seamless Transition of Microgrids Operation From GridConnected to Islanded Mode. IEEE Trans. Smart Grid 2020, 11, 2106-2114. [CrossRef]

69. Rezkalla, M.; Pertl, M.; Marinelli, M. Electric power system inertia: Requirements, challenges and solutions. Electr. Eng. 2018, 100, 2677-2693. [CrossRef]

70. Magdy, G.; Bakeer, A.; Shabib, G.; Elbaset, A.A.; Mitani, Y. Decentralized model predictive control strategy of a realistic multi power system automatic generation control. In Proceedings of the Nineteenth International Middle East Power Systems Conference, Cairo, Egypt, 19-21 December 2017. [CrossRef]

71. Kerdphol, T.; Rahman, F.S.; Watanabe, M.; Mitani, Y.; Turschner, D.; Beck, H.P. Enhanced virtual inertia control based on derivative technique to emulate simultaneous inertia and damping properties for microgrid frequency regulation. IEEE Access 2019, 7, 14422-14433. [CrossRef]

72. Tamrakar, U.; Hansen, T.M.; Tonkoski, R.; Copp, D.A. Model Predictive Frequency Control of Low Inertia Microgrids. In Proceedings of the 2019 IEEE 28th International Symposium on Industrial Electronics (ISIE), Vancouver, BC, Canada, 12-14 June 2019. [CrossRef]

73. Metzger, M.; Polakow, G. A Survey on Applications of Agent Technology in Industrial Process Control. IEEE Trans. Ind. Inform. 2011, 7, 570-581. [CrossRef]

74. Singh, V.P.; Mohanty, S.R.; Kishor, N.; Ray, P.K. Robust H-infinity load frequency control in hybrid distributed generation system. Int. J. Electr. Power Energy Syst. 2013, 46, 294-305. [CrossRef]

75. Khan, A.A.; Khan, M.Q.; Satti, S.G.; Adil, M. Robust control of hybrid distributed generation for frequency regulation. In Proceedings of the 2017 14th International Bhurban Conference on Applied Sciences and Technology (IBCAST), Islamabad, Pakistan, 10-14 January 2017. [CrossRef]

76. Fathi, A.; Shafiee, Q.; Bevrani, H. Robust Frequency Control of Microgrids Using an Extended Virtual Synchronous Generator. IEEE Trans. Power Syst. 2018, 33, 6289-6297. [CrossRef]

77. Manabe, S. Importance of coefficient diagram in polynomial method. In Proceedings of the 42nd IEEE International Conference on Decision and Control (IEEE Cat. No.03CH37475), Maui, HI, USA, 9-12 December 2003. [CrossRef]

78. Manabe, S. Coefficient diagram method in mimo application: An aerospace case study. IFAC Proc. Vol. 2005, 38, 7-12. [CrossRef]

79. Lipatov, A.V.; Sokolov, N.I. On some sufficient conditions for stability and instability of linear continuous stationary systems. Avtomat. iTelemekh. 1978, 39, 1285-1291.

80. Manabe, S. Coefficient Diagram Method as Applied to the Attitude Control of Controlled-Bias-Momentum Satellite. IFAC Proc. Vol. 1994, 27, 327-332. [CrossRef]

81. Ali, R.; Mohamed, T.H.; Qudaih, Y.S.; Mitani, Y. A new load frequency control approach in an isolated small power systems using coefficient diagram method. Int. J. Electr. Power Energy Syst. 2014, 56, 110-116. [CrossRef]

82. Coelho, J.P.; Boaventura-Cunha, J.; de Moura Oliveira, P.B. Extended Stability Conditions for CDM Controller Design; Springer International Publishing: Cham, Switzerland, 2015; pp. 171-182. [CrossRef]

83. Ali, H.; Magdy, G.; Xu, D. A new optimal robust controller for frequency stability of interconnected hybrid microgrids considering non-inertia sources and uncertainties. Int. J. Electr. Power Energy Syst. 2021, 106651. [CrossRef]

84. Sutton, R.S.; Barto, A.G. Reinforcement Learning: An Introduction, 2nd ed.; The MIT Press: Cambridge, MA, USA, 2018.

85. Lillicrap, T.P.; Hunt, J.J.; Pritzel, A.; Heess, N.; Erez, T.; Tassa, Y.; Silver, D.; Wierstra, D. Continuous control with deep reinforcement learning. arXiv 2019, arXiv:1509.02971.

86. Li, Y.; Gao, W.; Yan, W.; Huang, S.; Wang, R.; Gevorgian, V.; Gao, D.W. Data-Driven Optimal Control Strategy for Virtual Synchronous Generator via Deep Reinforcement Learning Approach. J. Mod. Power Syst. Clean Energy 2021, 1-11. [CrossRef]

87. Guo, W.; Liu, F.; Si, J.; Mei, S. Incorporating approximate dynamic programming-based parameter tuning into PD-type virtual inertia control of DFIGs. In Proceedings of the International Joint Conference on Neural Networks, Dallas, TX, USA, 4-9 August 2013. [CrossRef] 
88. Shrestha, D.; Tamrakar, U.; Malla, N.; Ni, Z.; Tonkoski, R. Reduction of energy consumption of virtual synchronous machine using supplementary adaptive dynamic programming. In Proceedings of the 2016 IEEE International Conference on Electro Information Technology (EIT), Grand Forks, ND, USA, 19-21 May 2016. [CrossRef]

89. Wang, D.; He, H.; Liu, D. Adaptive Critic Nonlinear Robust Control: A Survey. IEEE Trans. Cybern. 2017, 47, 3429-3451. [CrossRef] [PubMed]

90. Mokadem, M.E.; Courtecuisse, V.; Saudemont, C.; Robyns, B.; Deuse, J. Fuzzy Logic Supervisor-Based Primary Frequency Control Experiments of a Variable-Speed Wind Generator. IEEE Trans. Power Syst. 2009, 24, 407-417. [CrossRef]

91. Sa-ngawong, N.; Ngamroo, I. Optimal fuzzy logic-based adaptive controller equipped with DFIG wind turbine for frequency control in stand alone power system. In Proceedings of the 2013 IEEE Innovative Smart Grid Technologies-Asia (ISGT Asia), Bangalore, India, 10-13 November 2013. [CrossRef]

92. Mentesidi, K.; Garde, R.; Aguado, M.; Rikos, E. Implementation of a fuzzy logic controller for virtual inertia emulation. In Proceedings of the 2015 International Symposium on Smart Electric Distribution Systems and Technologies (EDST), Vienna, Austria, 8-11 September 2015. [CrossRef]

93. Hu, Y.; Wei, W.; Peng, Y.; Lei, J. Fuzzy virtual inertia control for virtual synchronous generator. In Proceedings of the 201635 th Chinese Control Conference (CCC), Chengdu, China, 27-29 July 2016. [CrossRef]

94. Chamorro, H.R.; Riaño, I.; Gerndt, R.; Zelinka, I.; Gonzalez-Longatt, F.; Sood, V.K. Synthetic inertia control based on fuzzy adaptive differential evolution. Int. J. Electr. Power Energy Syst. 2019, 105, 803-813. [CrossRef]

95. Mamdani, E.; Baaklini, N. Prescriptive method for deriving control policy in a fuzzy-logic controller. Electron. Lett. 1975, 11, 625. [CrossRef]

96. Wang, T.; Gao, H.; Qiu, J. A Combined Adaptive Neural Network and Nonlinear Model Predictive Control for Multirate Networked Industrial Process Control. IEEE Trans. Neural Netw. Learn. Syst. 2016, 27, 416-425. [CrossRef]

97. Kennedy, J.; Eberhart, R. Particle swarm optimization. In Proceedings of the ICNN95-International Conference on Neural Networks, Perth, WA, Australia, 27 November-1 December 1995; Volume 4, pp. 1942-1948. [CrossRef]

98. Gaing, Z.L. A Particle Swarm Optimization Approach for Optimum Design of PID Controller in AVR System. IEEE Trans. Energy Convers. 2004, 19, 384-391. [CrossRef]

99. Magdy, G.; Bakeer, A.; Nour, M.; Petlenkov, E. A New Virtual Synchronous Generator Design Based on the SMES System for Frequency Stability of Low-Inertia Power Grids. Energies 2020, 13, 5641. [CrossRef]

100. Qi, Z.; Shi, Q.; Zhang, H. Tuning of Digital PID Controllers Using Particle Swarm Optimization Algorithm for a CAN-Based DC Motor Subject to Stochastic Delays. IEEE Trans. Ind. Electron. 2020, 67, 5637-5646. [CrossRef]

101. Frack, P.F.; Mercado, P.E.; Molina, M.G. Extending the VISMA concept to improve the frequency stability in Microgrids. In Proceedings of the 2015 18th International Conference on Intelligent System Application to Power Systems (ISAP), Porto, Portugal, 11-16 September 2015. [CrossRef]

102. Hekimoglu, B. Optimal Tuning of Fractional Order PID Controller for DC Motor Speed Control via Chaotic Atom Search Optimization Algorithm. IEEE Access 2019, 7, 38100-38114. [CrossRef]

103. Chen, J.; Yang, F.; Han, Q.L. Model-Free Predictive H Control for Grid-Connected Solar Power Generation Systems. IEEE Trans. Control. Syst. Technol. 2014, 22, 2039-2047. [CrossRef]

104. Mariethoz, S.; Fuchs, A.; Morari, M. A VSC-HVDC Decentralized Model Predictive Control Scheme for Fast Power Tracking. IEEE Trans. Power Deliv. 2014, 29, 462-471. [CrossRef]

105. Han, H.G.; Zhang, L.; Hou, Y.; Qiao, J.F. Nonlinear Model Predictive Control Based on a Self-Organizing Recurrent Neural Network. IEEE Trans. Neural Netw. Learn. Syst. 2016, 27, 402-415. [CrossRef]

106. Kou, P.; Liang, D.; Yu, L.; Gao, L. Nonlinear Model Predictive Control of Wind Farm for System Frequency Support. IEEE Trans. Power Syst. 2019, 34, 3547-3561. [CrossRef]

107. Rout, U.K.; Sahu, R.K.; Panda, S. Design and analysis of differential evolution algorithm based automatic generation control for interconnected power system. Ain Shams Eng. J. 2013, 4, 409-421. [CrossRef]

108. Sathya, M.; Ansari, M.M.T. Load frequency control using Bat inspired algorithm based dual mode gain scheduling of PI controllers for interconnected power system. Int. J. Electr. Power Energy Syst. 2015, 64, 365-374. [CrossRef]

109. Vukojevic, A.; Lukic, S. Microgrid Protection and Control Schemes for Seamless Transition to Island and Grid Synchronization. IEEE Trans. Smart Grid 2020, 11, 2845-2855. [CrossRef]

110. European Comission. Orintations towards the First Strategic Plan for Horizon Europe; Technical Report; European Comission: Brussels, Belgium, 2018.

111. Wang, S.; Gangammanavar, H.; Eksioglu, S.D.; Mason, S.J. Stochastic Optimization for Energy Management in Power Systems With Multiple Microgrids. IEEE Trans. Smart Grid 2019, 10, 1068-1079. [CrossRef]

112. Zeng, P.; Li, H.; He, H.; Li, S. Dynamic Energy Management of a Microgrid Using Approximate Dynamic Programming and Deep Recurrent Neural Network Learning. IEEE Trans. Smart Grid 2019, 10, 4435-4445. [CrossRef]

113. Sedhom, B.E.; El-Saadawi, M.M.; Moursi, M.E.; Hassan, M.; Eladl, A.A. IoT-based optimal demand side management and control scheme for smart microgrid. Int. J. Electr. Power Energy Syst. 2021, 127, 106674. [CrossRef]

114. Li, Y.; Liu, H.; Liu, C.; Wei, C.; Jiang, W.; Wang, F.; Wang, Z. Study on AC-side dynamic braking-based fault ride-through control for islanded renewable energy system with grid-connected VSC-HVDC transmission. In Proceedings of the 2017 Chinese Automation Congress (CAC), Jinan, China, 20-22 October 2017. [CrossRef] 
115. Byrne, R.H.; Nguyen, T.A.; Copp, D.A.; Chalamala, B.R.; Gyuk, I. Energy Management and Optimization Methods for Grid Energy Storage Systems. IEEE Access 2017, 6, 13231-13260. [CrossRef]

116. Hannan, M.A.; Hussin, I.; Ker, P.J.; Hoque, M.M.; Lipu, M.S.H.; Hussain, A.; Rahman, M.S.A.; Faizal, C.W.M.; Blaabjerg, F. Advanced Control Strategies of VSC Based HVDC Transmission System: Issues and Potential Recommendations. IEEE Access 2018, 6, 78352-78369. [CrossRef]

117. Xu, Y.; Sun, H.; Gu, W.; Xu, Y.; Li, Z. Optimal Distributed Control for Secondary Frequency and Voltage Regulation in an Islanded Microgrid. IEEE Trans. Ind. Inform. 2019, 15, 225-235. [CrossRef]

118. Zidar, M.; Hatziargyriou, N.D.; Škrlec, D.; Capuder, T.; Georgilakis, P.S. Review of energy storage allocation in power distribution networks: Applications, methods and future research. IET Gener. Transm. Distrib. 2016, 10, 645-652. [CrossRef]

119. REN21. Renewables Global Futures Report: Great Debates towards 100\% Renewable Energy. 2018. Available online http: //www.ren21.net/future-of-renewables/global-futures-report/ (accessed on 4 March 2020).

120. Enang, W.; Bannister, C. Modelling and control of hybrid electric vehicles (A comprehensive review). Renew. Sustain. Energy Rev. 2017, 74, 1210-1239. [CrossRef]

121. Pourmousavi, S.A.; Patrick, S.N.; Nehrir, M.H. Real-Time Demand Response Through Aggregate Electric Water Heaters for Load Shifting and Balancing Wind Generation. IEEE Trans. Smart Grid 2014, 5, 769-778. [CrossRef]

122. Yang, M.; Wang, J.; An, J. Day-Ahead Optimization Scheduling for Islanded Microgrid Considering Units Frequency Regulation Characteristics and Demand Response. IEEE Access 2020, 8, 7093-7102. [CrossRef]

123. Guo, J.; Zhao, T.; Liu, W.; Zhang, J. Reliability Modeling and Assessment of Isolated Microgrid Considering Influences of Frequency Control. IEEE Access 2019, 7, 50362-50371. [CrossRef]

124. Zames, G. Feedback and optimal sensitivity: Model reference transformations, multiplicative seminorms, and approximate inverses. IEEE Trans. Autom. Control 1981, 26, 301-320. [CrossRef]

125. Yang, S.; Lei, Q.; Peng, F.Z.; Qian, Z. A Robust Control Scheme for Grid-Connected Voltage-Source Inverters. IEEE Trans. Ind. Electron. 2011, 58, 202-212. [CrossRef]

126. Mešanović, A.; Münz, U.; Heyde, C. Comparison of $\mathrm{H} \infty, \mathrm{H} 2$, and pole optimization for power system oscillation damping with remote renewable generation. IFAC-PapersOnLine 2016, 49, 103-108. [CrossRef]

127. Wutthithanyawat, C.; Wangnippamto, S. Design of Decentralized PID Controller with Coefficient Diagram Method Based on Inverted Decoupling for TITO System. In Proceedings of the 2018 International Electrical Engineering Congress (iEECON), Krabi, Thailand, 7-9 March 2018. [CrossRef]

128. Moharana, A.; Samarabandu, J.; Varma, R.K. Fuzzy supervised PI controller for VSC HVDC system connected to Induction Generator based wind farm. In Proceedings of the 2011 IEEE Electrical Power and Energy Conference, Winnipeg, MB, Canada, 3-5 October 2011. [CrossRef]

129. Mahmoud, M.S.; Abouheaf, M.; Sharaf, A. Reinforcement learning control approach for autonomous microgrids. Int. J. Model. Simul. 2019, 1-10. [CrossRef]

130. Yi, Z.; Zhao, X.; Shi, D.; Duan, J.; Xiang, Y.; Wang, Z. Accurate Power Sharing and Synthetic Inertia Control for DC Building Microgrids With Guaranteed Performance. IEEE Access 2019, 7, 63698-63708. [CrossRef] 